\title{
The Low-Molecular Weight Protein Arginine Phosphatase PtpB Affects Nuclease Production, Cell Wall Integrity, and Uptake Rates of Staphylococcus aureus by Polymorphonuclear Leukocytes
}

\author{
Mohamed Ibrahem Elhawy $\left.{ }^{1,2}{ }^{(}\right)$, Virginie Molle ${ }^{3}\left(\mathbb{D}\right.$, Sören L. Becker ${ }^{1}\left(\mathbb{D}\right.$ and Markus Bischoff ${ }^{1, *}$ \\ 1 Institute of Medical Microbiology and Hygiene, Saarland University, 66421 Homburg, Germany; \\ Mohamed.Elhawy@uks.eu (M.I.E.); soeren.becker@uks.eu (S.L.B.) \\ 2 Department of Pathology, Faculty of Veterinary Medicine, Zagazig University, Zagazig 44511, Egypt \\ 3 Laboratory of Pathogen Host Interactions, Université de Montpellier, CNRS, UMR 5235, \\ 34095 Montpellier, France; virginie.molle@umontpellier.fr \\ * Correspondence: markus.bischoff@uks.eu; Tel.: +49-6841-1623963
}

Citation: Elhawy, M.I.; Molle, V.; Becker, S.L.; Bischoff, M. The Low-Molecular Weight Protein Arginine Phosphatase PtpB Affects Nuclease Production, Cell Wall Integrity, and Uptake Rates of Staphylococcus aureus by Polymorphonuclear Leukocytes. Int. J. Mol. Sci. 2021, 22, 5342. https:// doi.org/10.3390/ijms22105342

Academic Editor: Juan

Francisco Martín

Received: 20 April 2021

Accepted: 17 May 2021

Published: 19 May 2021

Publisher's Note: MDPI stays neutral with regard to jurisdictional claims in published maps and institutional affiliations.

Copyright: (c) 2021 by the authors. Licensee MDPI, Basel, Switzerland. This article is an open access article distributed under the terms and conditions of the Creative Commons Attribution (CC BY) license (https:/ / creativecommons.org/licenses/by/ $4.0 /)$.
Abstract: The epidemiological success of Staphylococcus aureus as a versatile pathogen in mammals is largely attributed to its virulence factor repertoire and the sophisticated regulatory network controlling this virulon. Here we demonstrate that the low-molecular-weight protein arginine phosphatase PtpB contributes to this regulatory network by affecting the growth phase-dependent transcription of the virulence factor encoding genes/operons aur, nuc, and $p s m \alpha$, and that of the small regulatory RNA RNAIII. Inactivation of $p t p B$ in S. aureus SA564 also significantly decreased the capacity of the mutant to degrade extracellular DNA, to hydrolyze proteins in the extracellular milieu, and to withstand Triton X-100 induced autolysis. SA564 $\Delta p t p B$ mutant cells were additionally ingested faster by polymorphonuclear leukocytes in a whole blood phagocytosis assay, suggesting that PtpB contributes by several ways positively to the ability of S. aureus to evade host innate immunity.

Keywords: Staphylococcus aureus; low-molecular-weight protein arginine phosphatase; PtpB; nuclease; whole blood phagocytosis assay; cell wall integrity; gene transcription; Triton X-100 induced autolysis; innate immunity

\section{Introduction}

Staphylococcus aureus is a major bacterial pathogen in humans and animals [1]. The ability of this Gram-positive bacterium to respond accurately to changing environments is one of the prerequisites for its success as a versatile pathogen in mammals [2]. The opportunistic pathogen is equipped with an armamentarium of virulence factors and a sophisticated network of regulatory molecules allowing it to control/fine-tune the expression of its virulon in a way to rapidly respond to changing conditions [3]. While virulence factor synthesis in S. aureus is mainly driven by one component systems such as the Sar family of DNA binding proteins and two-component system (TCS) response regulators [4], phosphatases are also known to contribute to this network. Earlier work demonstrated, for instance, that the serine/threonine phosphatase Stp1 directly contributes to virulence factor synthesis and infectivity of $S$. aureus by promoting the transcription of the $\alpha$-hemolysin encoding gene $h l a[5]$. More recent data indicate that the low-molecular-weight protein arginine phosphatase (LMW-PAP) PtpB might also contribute to staphylococcal pathophysiology by modulating the arginine phosphorylation states of regulators such as the stress response regulator CtsR and the global regulator MgrA, particularly in response to oxidative stress [6,7]. A deletion of $p t p B$ in the S. aureus clinical isolate SA564 was additionally shown lately to reduce the capacity of the mutant to survive inside of macrophages and to cause infection in a murine-based S. aureus abscess model [8]. PtpB might thereby 
form a regulatory circuit with $\mathrm{McsB}$, the presumed protein arginine kinase of $S$. aureus, which is part of the $\operatorname{clpC}$ operon and known to affect the hemolytic and proteolytic activity of this bacterium [9]. The McsB homolog in Bacillus subtilis was shown to modulate the activity of McsB-targeted regulators by phosphorylating arginine residues within the DNA-binding domains and by marking proteins and aberrant polypeptide molecules for degradation [10,11]; similar functions are assumed for McsB in S. aureus [6]. Thus, by counteracting McsB-dependent arginine phosphorylation of the aforementioned global regulators, PtpB might affect the activity and stability of these transcription factors and thus the expression of stress response genes and virulence factors that are directly and/or indirectly controlled by these regulatory molecules. Additionally, PtpB might interfere with the degradation process of proteins phosphorylated at arginine residues. Notably, a functional classification of arginine phosphorylated proteins found in in vitro cultured S. aureus cells carried out by Junker et al. [6] revealed that nearly half $(47 \%)$ of the identified arginine phosphoproteins in the $p t p B$ mutant could be associated with virulence functions, supporting the idea that $\mathrm{PtpB}$ contributes to the regulatory network controlling the virulence factor synthesis in this bacterial pathogen.

In this study, we further strengthen this assumption by demonstrating that inactivation of $p t p B$ in S. aureus strain SA564-a whole genome sequenced clinical human isolate of the worldwide distributed clonal complex 5 that harbors functional agr and sigB operons and a saes ${ }^{\mathrm{L}}$ allele [12,13] —affects the transcription of the virulence factor encoding genes aur (encoding the zinc-metalloprotease aureolysin), nuc (encoding thermonuclease) and $p s m \alpha$ (encoding the phenol-soluble modulins $\alpha 1-4$ ), and of the small regulatory RNA RNAIII, one of the master regulators controlling exoprotein synthesis in this bacterium [14], which also encodes a protein, $\delta$-hemolysin (Hld). Deletion of $p t p B$ also impedes the capacity of $S$. aureus to evade phagocytosis by polymorphonuclear leukocytes (PMNs), to withstand Triton X100 induced autolysis or lysostaphin mediated lysis, and decreases the exonuclease- and exoprotease activities of this bacterium.

\section{Results and Discussion}

\subsection{PtpB Affects the Ability of S. aureus to Evade Phagocytosis by PMNs}

Recent work demonstrated that PtpB contributes to the ability of $S$. aureus to survive inside macrophages [8]. However, it remains unknown whether PtpB also supports the capacity of the pathogen to evade innate immunity. In order to address this issue, we first investigated the impact of a $p t p B$ deletion on attachment/phagocytosis of S. aureus SA564 by PMNs in whole blood (Figure 1).

When human blood was supplemented with fluorescent-labeled bacteria at a multiplicity of infection (MOI) of 50 per PMNs, a clear difference in uptake rates of $p t p B$ negative and positive S. aureus SA564 cells by human PMNs was observed (Figure 1). After $30 \mathrm{~min}$ of coincubation in human whole blood, CFSE-stained SA564 isolates harboring a functional $p t p B$ (wild-type and cis-complemented derivative) demonstrated significantly decreased rates of attachment/phagocytosis by PMNs compared to the CFSE-stained SA564 derivative lacking $p t p B$ (SA564 $\triangle p t p B$ ). These findings suggest that PtpB mediates a relevant protective effect against phagocytosis by PMNs in blood. 


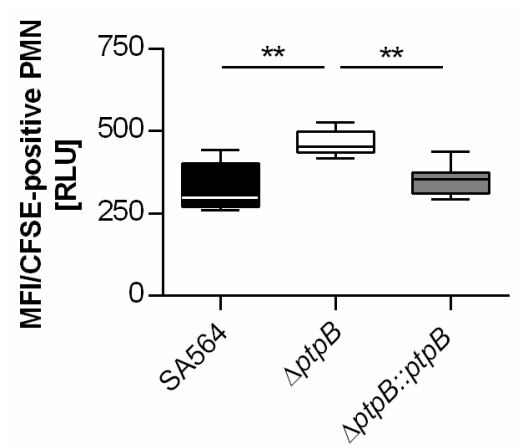

Figure 1. Effect of PtpB on phagocytosis of S. aureus SA564 by polymorphonuclear leukocytes (PMNs). Carboxy fluorescein diacetate succinimidyl ester (CFSE)-stained cells of S. aureus SA564 (black boxes), SA564 $\Delta p t p B$ (white boxes), and SA564 $\Delta p t p B:: p t p B$ (gray boxes) were added to lithium heparin anticoagulated fresh human blood at a multiplicity of infection of 50 per PMN, and incubated for $30 \mathrm{~min}$ at $37^{\circ} \mathrm{C}$ and $1000 \mathrm{rpm}$. Attachment/uptake of bacteria by PMNs was analyzed by flow cytometry as outlined in Material and Methods. The data are representative of three biological replicates carried out in triplicate. Data are presented as box and whisker plots showing the interquartile range (25-75\%; box), median (horizontal line), and whiskers (bars; $\mathrm{min} / \mathrm{max}$ ). ${ }^{* *} p<0.01$ (Kruskal-Wallis test followed by Dunn's post hoc test).

\subsection{PtpB Promotes the Transcription and Secretion of Nuclease in S. aureus}

Neutrophils are the main pathogen-fighting immune cells in our blood system [15]. Besides their capacity to ingest circulating pathogens, activated neutrophils exert a number of cytotoxic functions such as the production of reactive oxygen and nitrogen species, the release of antimicrobial peptides, and the formation of extracellular DNA nets called neutrophil extracellular traps (NETs) [15]. The latter bacteria-capturing and killing mechanism is counteracted by S. aureus, among others, via the secretion of nucleases and the extracellular adherence protein (Eap), which degrade and aggregate NETs, respectively [16,17]. We have recently shown that PtpB supports the capacity of $S$. aureus to cope with oxidative and nitrosative stress [8]. To test whether PtpB might also interfere with other neutrophilderived cytotoxic activities, we next tested whether the LMW-PAP might modulate the capacity of S. aureus to degrade extracellular DNA (Figure 2).

When cell suspensions of SA564 and the cis-complemented $\triangle p t p B:: p t p B$ derivative were spotted on DNase test agar plates and incubated at $37^{\circ} \mathrm{C}$ for $24 \mathrm{~h}$, clearly visible lytic areas around the bacterial growth areas were observed that were in comparable ranges (Figure 2a,b). However, when equal volumes of SA564 $\Delta p t p B$ cell suspensions were spotted onto the DNase test agar plates, significantly smaller lytic areas surrounding the bacterial growth zones were observed, suggesting that the $\triangle p t p B$ mutant produces and/or secretes lower amounts of nucleases into the extracellular milieu.

To elucidate whether the reduced nuclease activity observed with the $\triangle p t p B$ mutant might be due to PtpB-induced changes in $n u c$ transcription, we next assayed the transcription rates of nuc in SA564 and its $\triangle p t p B$ derivative upon growth in tryptic soy broth (TSB) over time. Specifically, total RNAs were obtained from cell populations grown for $3 \mathrm{~h}$ (exponential growth phase), $5 \mathrm{~h}$ (transition phase), and $8 \mathrm{~h}$ (early stationary phase), respectively (Figure 2c). In line with our DNase activity findings, we observed a significantly reduced transcription of $n u c$ in SA564 $\triangle p t p B$ cells at two of the three growth stages analyzed, if compared to the wild-type transcript level, while cells of the cis-complemented derivative produced nuc transcript level that were comparable to the wild-type. Taken together, these findings suggest that $\mathrm{PtpB}$ contributes positively to the exonuclease activity of $S$. aureus by supporting $n u c$ transcription. 
(a)
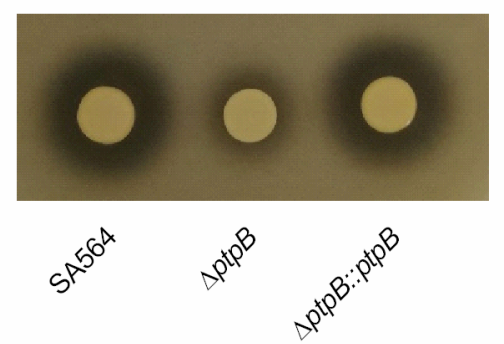

(c)

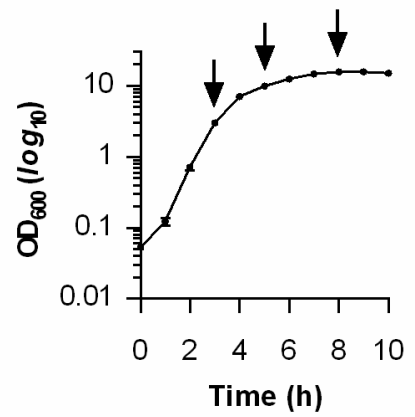

(b)

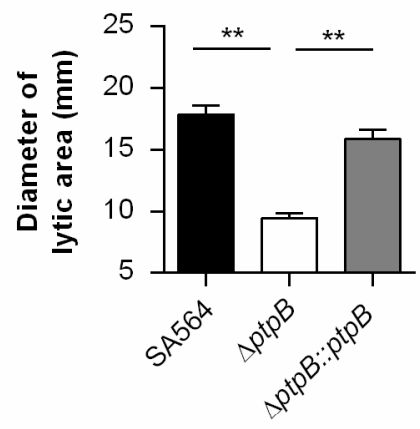

(d)

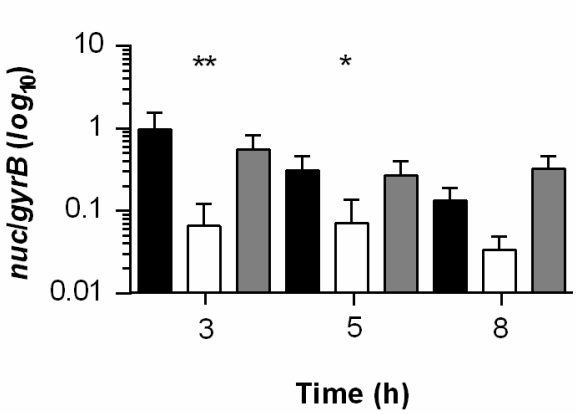

Figure 2. Effect of PtpB on extracellular DNase activity and nuc transcription of S. aureus SA564. $(\mathbf{a}, \mathbf{b})$ Impact of PtpB on extracellular DNase activity. Overnight cultures of S. aureus strain SA564 (black bars), its isogenic $\triangle p t p B$ mutant (white bars), and the cis-complemented derivative (gray bars) were normalized with fresh tryptic soy broth (TSB) medium to an optical density at $600 \mathrm{~nm}\left(\mathrm{OD}_{600}\right)$ of 12 , and $5 \mu \mathrm{L}$ of the suspensions spotted on DNase-Test-Agar plates. Inoculated plates were cultured for $24 \mathrm{~h}$ at $37^{\circ} \mathrm{C}$, and lytic areas were determined. (a) Representative image of one experiment. (b) Diameter of lytic areas. The data presented are the mean $+\mathrm{SD}$ of three biological experiments done in duplicate. ${ }^{* *} p<0.01$ (Kruskal-Wallis test followed by Dunn's post hoc test). (c) Growth kinetics of S. aureus strain SA564 in TSB. Cells were cultured at $37^{\circ} \mathrm{C}$ and $225 \mathrm{rpm}$ at a culture to flask volume of 1:10. Data represent the mean $\mathrm{OD}_{600}$ readings $\pm \mathrm{SD}$ at the time points indicated $(n=3)$. Time points of sampling for the transcriptional analyses are indicated by arrows. (d) Impact of PtpB on transcription of the thermonuclease encoding nuc gene. Quantitative transcript analyses of $n u c$ by qRT-PCR in SA564 (black bars), SA564 $\triangle p t p B$ (white bars), and SA564 $\triangle p t p B:: p t p B$ (gray bars) cells grown to the time points indicated. Transcript rates were quantified in reference to the transcription of gyrase B (in copies per copy of gyrB). Data are presented as mean $+\mathrm{SD}$ of five biological replicates. ${ }^{*} p<0.05 ;{ }^{* *} p<0.01$ (Kruskal-Wallis test followed by Dunn's post hoc test between wild-type and mutants at a given time point).

\subsection{PtpB Promotes the Transcription of the Aureolysin Encoding Gene aur in S. aureus}

Another major virulence determinant interfering with innate host immunity and supporting the survival of $S$. aureus in blood is the zinc-metalloprotease aureolysin, which cleaves, among others, various factors of the human complement system [18]. To test whether PtpB might aid the immune evasion of S. aureus by modulating aureolysin expression, we tested the transcription of aur during growth in TSB (Figure 3a). This transcriptional analysis revealed a significantly decreased number of aur transcripts in exponential growth phase cells of the $p t p B$ deletion mutant when compared with cells of the wild-type and the cis-complemented derivative harvested at the same growth stage, respectively. However, aur transcript rates were rather comparable between wild-type, $\Delta p t p B$ mutant, and cis-complemented cells obtained from later growth stages (i.e., 5 and $8 \mathrm{~h}$ of growth), suggesting that PtpB contributes to aur expression primarily in S. aureus exponential growth phase cells. 
(a)

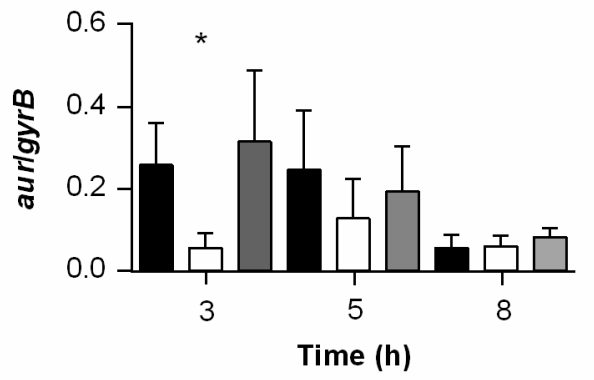

(c)

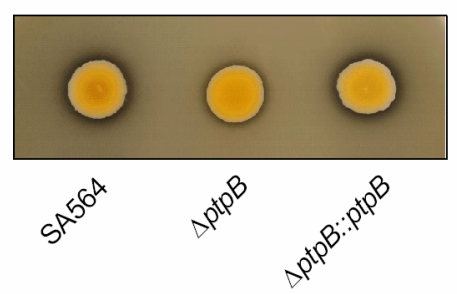

(b)

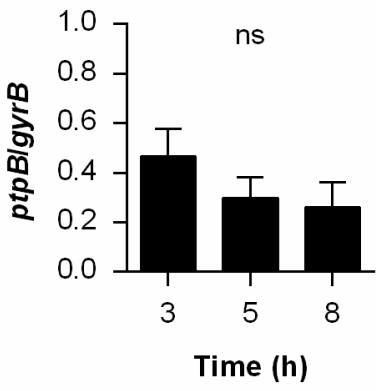

(d)

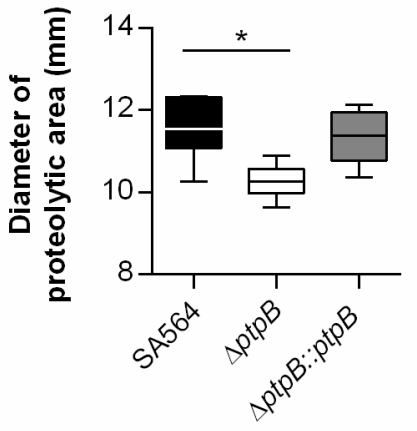

Figure 3. Effect of a $p t p B$ deletion on the transcription of aur and the proteolytic activity of $S$. aureus SA564. (a) Quantitative transcript analyses of aur by qRT-PCR in SA564 (black bars), SA564 $\Delta p t p B$ (white bars), and SA564 $\triangle p t p B:: p t p B$ (gray bars) cells grown in tryptic soy broth (TSB) at $37^{\circ} \mathrm{C}$ and $225 \mathrm{rpm}$ to the time points indicated. Transcript rates were quantified in reference to the transcription of gyrase B (in copies per copy of $g y r B$ ). Data are presented as mean $+\mathrm{SD}$ of four to five biological replicates. ${ }^{*} p<0.05$ (Kruskal-Wallis test followed by Dunn's post hoc test between wild-type and mutants at a given time point). (b) Quantitative transcript analyses of $p t p B$ by qRT-PCR in SA564 cells grown in TSB. Sampling and transcription rate quantifications were done as described above. Data are presented as mean $+\mathrm{SD}$ of five biological replicates. (c,d) Impact of PtpB on extracellular protease activity. Overnight cultures of $S$. aureus strain SA564 (black bars), its isogenic $\Delta p t p B$ mutant (white bars), and the cis-complemented SA564 $\triangle p t p B:: p t p B$ derivative (gray bars) were normalized with fresh TSB medium to an $\mathrm{OD}_{600}$ of 12 , and $2 \mu \mathrm{L}$ of the suspensions spotted on TSA plates supplemented with $10 \%$ skim milk. Inoculated plates were cultured for $48 \mathrm{~h}$ at $37{ }^{\circ} \mathrm{C}$, and proteolytic areas were determined. (c) Representative image of one experiment. (d) Diameter of proteolytic areas. The data presented are the mean $+\mathrm{SD}$ of three biological experiments done in duplicate. ns, not significant; ${ }^{*} p<0.05$ (Kruskal-Wallis test followed by Dunn's post hoc test).

To get an idea about whether the impact of PtpB on aur transcription might correlate with the expression of the LMW-PAP, we determined the transcription rates of $p t p B$ in SA564 during growth in TSB (Figure 3b). These analyses revealed that $p t p B$ is transcribed on a rather constant level throughout growth (fold changes in relative transcription rates between growth stages $<2$ ), suggesting that the growth phase-dependent effect of PtpB on aur transcription is not likely to be determined by the expression rates of the LMW-PAP during growth.

Besides its complement factors degrading functions [18], aureolysin is also known for its capacity to process and thus activate serine protease SspA (syn. V8 protease), another major exoprotease produced by S. aureus, which in turn cleaves the propeptide from the $\mathrm{SspB}$ zymogen to create the active cysteine protease SspB (syn. staphopain), a process also known as staphylococcal proteolytic cascade [19].

Wondering whether PtpB might also affect the exoproteolytic capacity of S. aureus, we conducted a series of skim milk agar-based protease assays (Figure 3c,d). Stationary phase cell suspensions of SA564 normalized to an $\mathrm{OD}_{600}$ of 12 spotted onto the skim 
milk supplemented tryptic soy agar (TSA) plates produced only very small proteolytic areas surrounding the bacterial growth zones after $48 \mathrm{~h}$ of incubation at $37^{\circ} \mathrm{C}$ (Figure 3c). However, when normalized stationary phase cell suspensions of SA564 $\Delta p t p B$ were spotted onto the skim milk TSA plates, significantly smaller proteolytic areas were observed, while cell suspensions of the cis-complemented SA564 $\triangle p t p B:: p t p B$ produced proteolytic areas on skimmed milk TSA plates that were in a comparable range to those seen with the wild-type cultures (Figure $3 c, d$ ). These findings suggest that PtpB affects the proteolytic capacity of S. aureus, potentially via the modulation of aur transcription.

\subsection{PtpB Reduces the Autolytic Activity of S. aureus}

Activated neutrophils secrete, among others, antimicrobial peptides (e.g., defensins) which exert potent in vitro microbicidal activity against $S$. aureus through mechanisms involving cell membrane destabilization, interference with intracellular targets, and activation of autolysins [20]. To test whether and how PtpB might influence the autolytic behavior of $S$. aureus, we next studied the impact of the $p t p B$ deletion on the autolytic behavior of SA564 in Triton X-100- and lysostaphin-induced lysis assays, respectively (Figure 4).

(a)

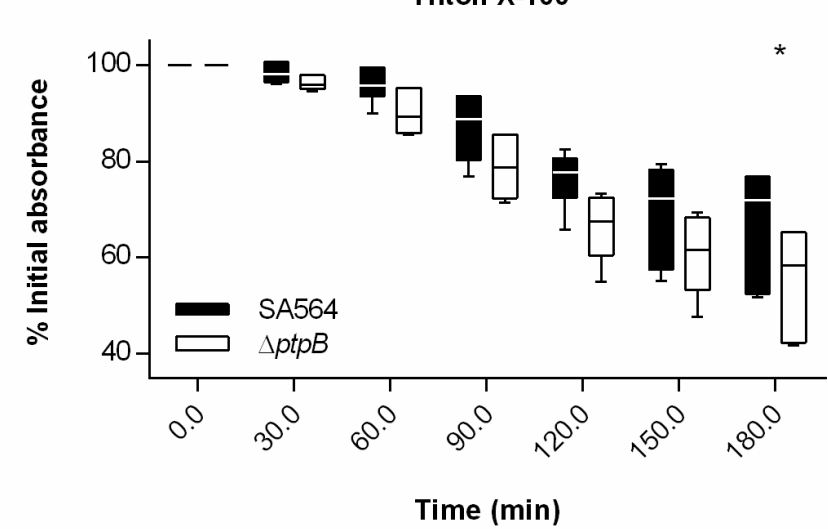

(b)

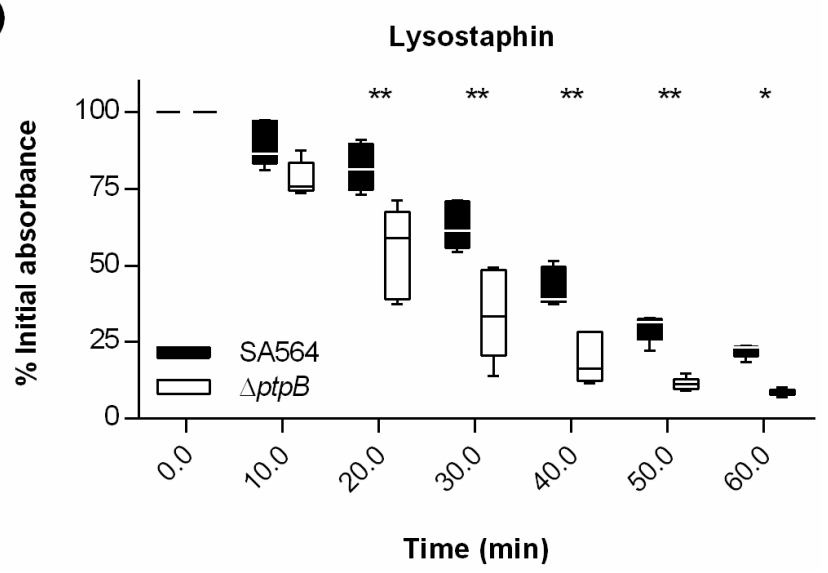

Figure 4. Effect of a $p t p B$ deletion on the Triton X-100 induced autolysis and lysostaphin-mediated lysis of S. aureus SA564. (a) Cells of S. aureus strain SA564 (black symbols) and its isogenic $\triangle p t p B$ mutant (white symbols) were cultured in TSB at $37^{\circ} \mathrm{C}$ and $225 \mathrm{rpm}$ to an $\mathrm{OD}_{600}$ of 0.7 , washed twice in ice-cold water, and resuspended in $0.05 \mathrm{M} \mathrm{Tris-} \mathrm{HCl}$ (pH 7.2) containing $0.01 \%$ (vol/vol) Triton X-100. Triton X-100 induced autolysis was measured as the decline of optical density at $600 \mathrm{~nm}\left(\mathrm{OD}_{600}\right)$ versus time and is expressed as the percent of the initial optical density ( $n=6$ biological replicates). (b) Effect of a $p t p B$ deletion on the lysostaphin-mediated lysis. Cells of S. aureus strain SA564 (black symbols) and its isogenic $\Delta p t p B$ mutant (white symbols) were cultured in TSB at $37^{\circ} \mathrm{C}$ and $225 \mathrm{rpm}$ to an $\mathrm{OD}_{600}$ of 3 , washed twice in PBS, and resuspended in PBS to an $\mathrm{OD}_{600}$ of 1 . The PBS cell suspensions were supplemented with $250 \mathrm{ng} / \mathrm{mL}$ lysostaphin and incubated under static conditions at $30{ }^{\circ} \mathrm{C}$ for $60 \mathrm{~min}$. Lysostaphin-mediated lysis was measured as the decline of $\mathrm{OD}_{600}$ versus time and is expressed as the percent of the initial optical density ( $n=5$ biological replicates). Data are presented as box and whisker plots showing the interquartile range (25-75\%; box), median (horizontal line), and whiskers (bars; $\min / \max$ ). ${ }^{*} p<0.05$; ** $p<0.01$ (Ordinary two-way ANOVA followed by Holm-Sidak's multiple comparison test).

When washed exponential growth phase cells of SA564 and its $\triangle p t p B$ mutant were challenged with a low dose of Triton X-100, respectively, cells of the $p t p B$ deletion mutant autolyzed to a significantly larger extent after $3 \mathrm{~h}$ of coincubation with the detergent than wild-type cells (Figure 4a). A similar behavior was observed when SA564 and its $\triangle p t p B$ mutant were challenged with the glycyl-glycyl endopeptidase lysostaphin, a S. aureus pentaglycine cross-bridges cleaving exoenzyme from Staphylococcus simulans bv. staphylolyticus [21]. Washed and PBS resuspended late exponential growth phase cells of the $p t p B$ deletion mutant lysed again significantly faster than the wild-type cells (Figure $4 b$ ), indicating that PtpB is likely to affect the cell wall composition of $S$. aureus. One possible explanation for both observations is that PtpB might interfere with the production and/or 
activation of autolysins (e.g., endogenous murein hydrolases), as has been suggested for the lysostaphin resistance of some glycopeptide-intermediate-resistant S. aureus (GISA) [22].

As previous studies have already demonstrated that the global regulator MgrA acts as a repressor of autolysins in S. aureus [23,24], and that MgrA serves as a substrate for PtpB $[6,7]$, it was tempting to speculate that PtpB might affect the autolytic behavior of S. aureus via modulation of MgrA activity. In order to address this hypothesis, we first studied the impact of the $p t p B$ deletion on the transcription of MgrA regulated genes [25,26], focusing on genes whose products are involved in the autolytic behavior of $S$. aureus (Figure 5). Specifically, the transcription of atlR (encoding a MarR family transcriptional regulator repressing atl transcription), $f m t B$ (encoding a cell wall-anchored protein involved in methicillin resistance and cell wall biosynthesis), $\operatorname{lrg} A$ (encoding the holin-like murein hydrolase regulator $\operatorname{Lrg} \mathrm{A}$ ), and $l y t N$ (encoding the cell-wall hydrolase $\mathrm{LytN}$ ) was analyzed, all of which were reported to directly or indirectly affect the autolytic behavior of S. aureus [27-29].

(a)

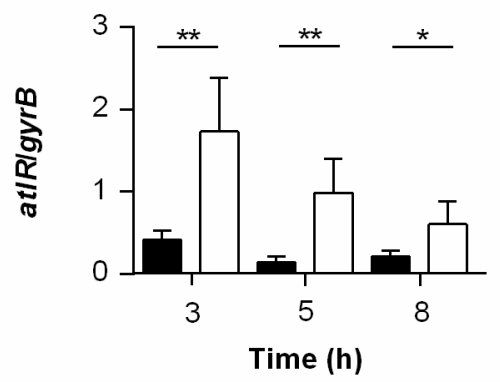

(c)

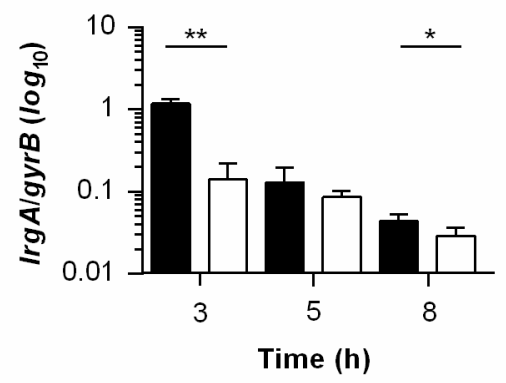

(b)

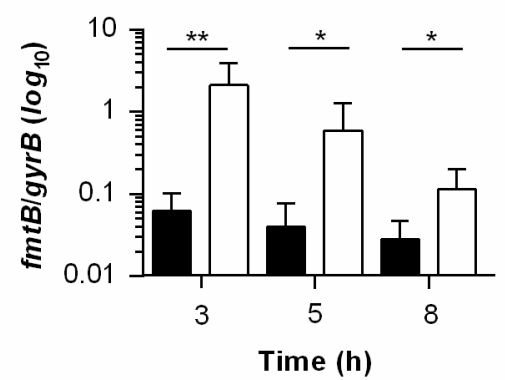

(d)

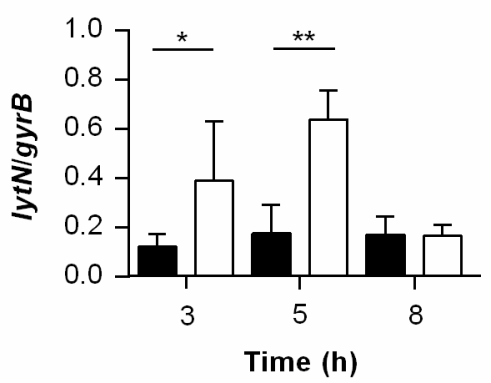

Figure 5. Effect of a $p t p B$ deletion on the transcription of MgrA-regulated genes affecting autolysis of S. aureus. Quantitative transcript analyses of MgrA regulated genes by qRT-PCR in SA564 (black bars) and SA564 $\triangle p t p B$ (white bars) cells grown in TSB at $37^{\circ} \mathrm{C}$ and $225 \mathrm{rpm}$ to the time points indicated. Growth-phase-dependent transcript rates of MgrA-regulated genes atlR $(\mathbf{a}), f \operatorname{tmB}(\mathbf{b}), \operatorname{lrg} A(\mathbf{c})$, and lytN (d). Transcript rates were quantified in reference to the transcription of gyrase B (in copies per copy of gyrB). Data are presented as mean $+\mathrm{SD}$ of five biological replicates. ${ }^{*} p<0.05 ;{ }^{* *} p<0.01$ (Mann-Whitney-U test between wild-type and mutant at a given time point).

Notably, all four MgrA-regulated genes were transcribed in a significantly different manner in SA564 $\triangle p t p B$ cells than in wild-type cells. Importantly, genes reported to be repressed by MgrA (i.e., atlR, $f m t B$, and $l y t N$ ) were all transcribed on higher levels in the $\operatorname{ptp} B$ deletion mutant, while transcription of $\operatorname{lrg} A$, which is positively affected by MgrA activity [25], was increased in wild-type cells throughout growth. However, while transcription of $a t l R, f m t B$, and $\operatorname{lrg} A$ was affected by the $p t p B$ deletion basically at all three growth stages (Figure $5 \mathrm{a}-\mathrm{c}$ ), this was not the case with lytN. Transcription of the cell-wall hydrolase encoding gene was only affected by the $p t p B$ deletion during exponential growth phase and transition phase, but not in the early stationary phase (Figure 5d), suggesting that $l y t N$ expression in the stationary phase cells is dominated by PtpB/MgrA-independent mechanisms. Taken together, these data indicate that the PtpB-driven dephosphorylation 
of MgrA phosphoarginine residues observed by Junker et al. [6] is likely to affect MgrA activity, and supports our hypothesis that PtpB interferes with autolysis of S. aureus via modulation of MgrA activity.

\subsection{PtpB Does Not Alter MgrA Activity per Se}

Given that MgrA also promotes the transcription of aur and nuc [25], which were also found to be transcribed in significantly higher levels in wild-type cells when compared to $\triangle p t p B$ mutant cells (Figures $2 \mathrm{c}$ and 3 ), we wondered whether PtpB might affect the transcription of the whole MgrA regulon. In order to address this hypothesis, we additionally tested the transcription of two MgrA-regulated surface factor encoding genes, $e b h$ (encoding extracellular matrix-binding protein Ebh) and spa (encoding immunoglobulin $\mathrm{G}$ binding protein $\mathrm{A}$ ), both of which are known to be strongly repressed by MgrA activity on the transcriptional level [26]. In contrast to findings obtained for the MgrA-regulated genes affecting autolysis (Figure 5), we surprisingly observed no clear differences in transcription rates of $e b h$ and spa between the wild-type and the $p t p B$ deletion mutant at any time point analyzed (Figure 6).

(a)

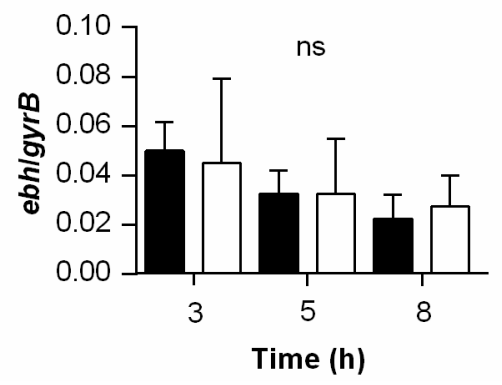

(b)

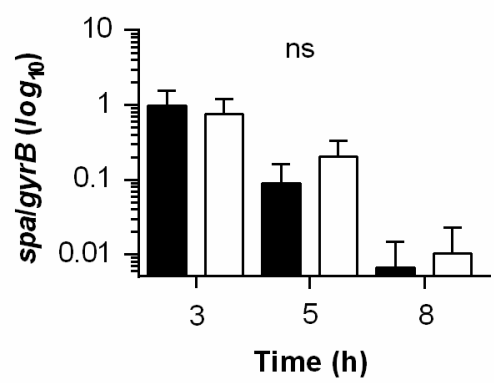

Figure 6. Effect of a $p t p B$ deletion on the transcription of MgrA-repressed surface factors encoding genes. Quantitative transcript analyses of MgrA-regulated genes ebh (a) and $s p a(\mathbf{b})$ by qRT-PCR in SA564 (black bars) and SA564 $\triangle p t p B$ (white bars) cells grown in TSB at $37^{\circ} \mathrm{C}$ and $225 \mathrm{rpm}$ to the time points indicated. Transcript rates were quantified in reference to the transcription of gyrase $B$ (in copies per copy of $g y r B$ ). Data are presented as mean $+\mathrm{SD}$ of five biological replicates. ns, not significant (Mann-Whitney-U test between wild-type and mutant at a given time point).

As MgrA directly represses ebh transcription [26], our findings presented here indicate that PtpB-driven dephosphorylation of MgrA does not alter the activity of the transcription factor towards its regulon per se, but might be important for the expression of a subset of MgrA-regulated factors, particularly of those involved in autolysis. One explanation for our observations might be that PtpB-mediated dephosphorylation of MgrA arginine residues influences the activity of the regulator by differentiating the binding specificity among target gene promoters, depending on the phosphorylation status at arginine residues. In such a scenario, target genes with a high binding affinity for MgrA would not be affected in their expression by the arginine phosphorylation status of the regulator and thus would not display a change in transcription depending on the PtpB status of the cell.

\subsection{PtpB Alters the Transcription of Some but Not All SarA Regulated Genes}

Transcription of aur, $\operatorname{lrg} A$, and nuc is also reported to be affected by SarA [30-32], suggesting that PtpB might also interfere with the transcription of the aforementioned genes via modulation of SarA activity, although SarA was not identified as a direct substrate for McsB/PtpB [6,7]. To test whether and how PtpB affects the transcription of the SarA regulon in SA564, we assayed the transcription rates of three additional SarA target genes, hla (encoding $\alpha$-hemolysin), hld (encoding $\delta$-hemolysin), and splB (encoding serine protease SplB; Figure 7) [32-34], which all contain a putative Sar box within the gene/operon's promoter region [32]. Similar to the situation seen with MgrA-regulated genes, we found 
significant changes in transcription rates in $p t p B$ lacking cells for some but not all SarAregulated genes. While transcription of the hld encoding RNAIII was affected by the $p t p B$ deletion during the exponential growth phase and early stationary phase (Figure $7 \mathrm{~b}$ ), this was neither the case with hla nor splB (Figure $7 \mathrm{a}, \mathrm{c}$ ). Notably, exponential growth phase cells of the $p t p B$ mutant produced lower RNAIII transcript rates than wild-type cells, while the opposite was encountered with early stationary phase cells, suggesting PtpB to modulate the transcription of the agr locus in SA564 by several means.

(a)

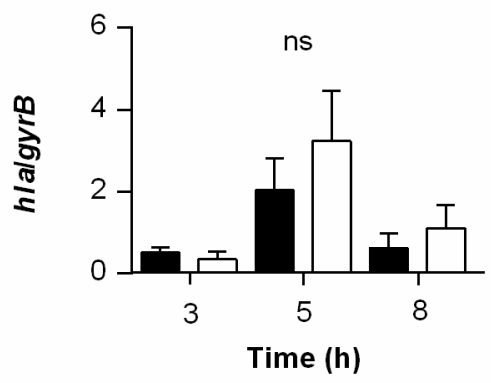

(d)

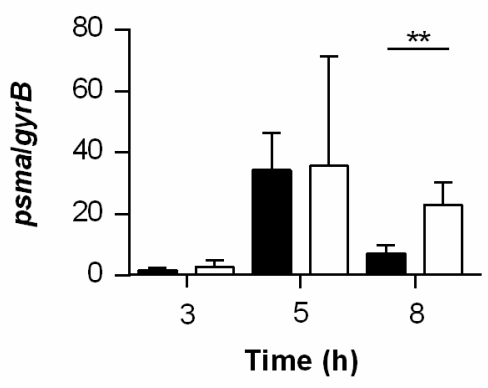

(b)

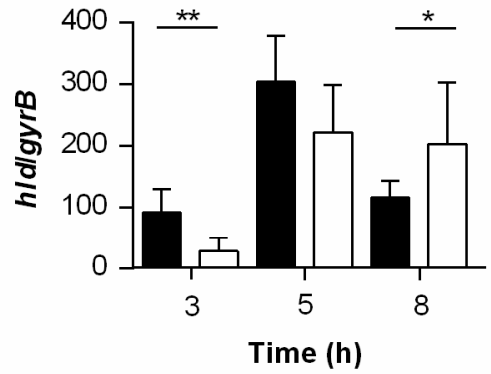

(e)

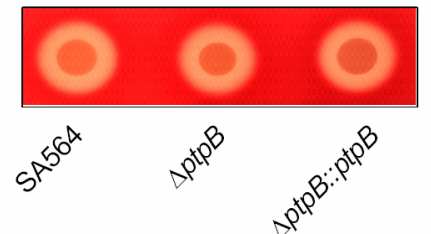

(c)

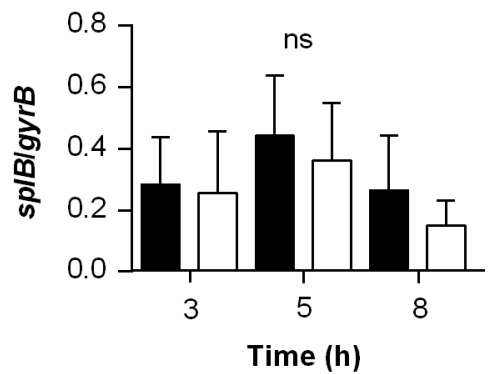

(f)

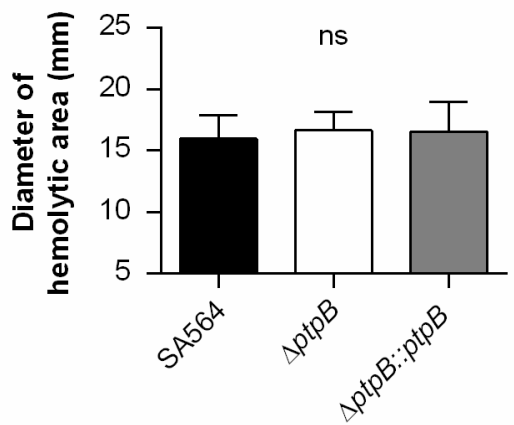

Figure 7. Effect of a $p t p B$ deletion on the transcription of SarA- and/or AgrA-regulated genes in S. aureus SA564. (a-d) Quantitative transcript analyses of SarA- and/or AgrA-regulated genes by qRT-PCR in SA564 (black bars) and SA564 $\triangle p t p B$ (white bars) cells grown in TSB at $37^{\circ} \mathrm{C}$ and $225 \mathrm{rpm}$ to the time points indicated. Growth phase-dependent transcript rates of Sar box containing genes hla $(\mathbf{a})$, hld (b), and $s p l B(\mathbf{c})$, and of the AgrA-driven psma cluster (d). Transcript rates were quantified in reference to the transcription of gyrase B (in copies per copy of gyrB). Data are presented as mean + SD of five biological replicates. ${ }^{*} p<0.05 ; * * p 0.01$; ns, not significant (Mann-Whitney-U test between wild-type and mutant at a given time point). (e,f) Overnight cultures of S. aureus strain SA564 (black bar), its isogenic $\triangle p t p B$ mutant (white bar), and the cis-complemented SA564 $\triangle p t p B:: p t p B$ derivative (gray bar) were normalized with fresh TSB medium to an $\mathrm{OD}_{600}$ of 12 , and $5 \mu \mathrm{L}$ of the suspensions spotted on sheep blood agar plates. Inoculated plates were cultured for $24 \mathrm{~h}$ at $37^{\circ} \mathrm{C}$, and hemolytic areas were determined. (e) Representative image of one experiment. (f) Diameter of hemolytic areas. The data presented are the mean $+\mathrm{SD}$ of three biological experiments done in duplicate. ns, not significant (Kruskal-Wallis test followed by Dunn's post hoc test).

One potential factor contributing to this phenomenon could be AgrA, the response regulator of the agr locus, and the main transcription factor driving RNAIII transcription [35]. Since AgrA is also known to control the expression of the phenol-soluble modulin operons $p s m \alpha$ and $p s m \beta$ [36], we additionally tested whether $p s m \alpha$ transcription in SA564 is altered by the $p t p B$ deletion (Figure $7 \mathrm{~d}$ ). In line with our RNAIII transcription data (Figure $7 \mathrm{~b}$ ), we observed significantly increased $p s m \alpha$ transcript rates in early stationary phase cells of the $\triangle p t p B$ mutant, suggesting that PtpB might modulate RNAIII and $p s m \alpha$ transcription in stationary phase cells via AgrA.

To support our transcriptional findings indicating that PtpB does not markedly alter the expression of $\alpha$-hemolysin in SA564, we tested the hemolytic activity of our strain triplet on sheep blood agar plates (Figure $7 \mathrm{e}, \mathrm{f})$. In line with our hla transcription findings, 
we did not encounter clear differences in the hemolytic areas surrounding the growth zones for all three SA564 derivatives.

Together with the observations that SarA was not identified to be phosphorylated at arginine residues [6,7], our transcriptional findings made for the Sar box-containing genes hla, spa, and splB suggest that PtpB is not likely to directly modulate SarA activity, albeit of the fact that the transcription rates of other Sar box containing genes such as aur, hld, and $n u c$ (Figures $2 c, 3$ and $7 b$ ) were markedly affected by the $p t p B$ deletion. The differences in transcription rates observed for the latter genes between the wild-type and the $p t p B$ deletion mutant might be attributed to other direct PtpB mediated effects on regulatory factors such as MgrA and AgrA, and/or indirect PtpB effects on regulators such as ArlR, CodY, SaeR, SarR, SarV, SarX, and SarZ, which all were found to be expressed to different extents in wild-type and $p t p B$ deletion mutant cells of $S$. aureus strain COL under non-stress conditions [6].

\section{Conclusions}

Protein posttranslational modifications such as reversible phosphorylation by kinases/phosphatases is a common mechanism employed by bacteria and eukaryotes to modulate the activity of enzymes and regulatory molecules, which is also utilized by S. aureus to adjust central metabolic pathways and virulence factor synthesis [37]. The serine/threonine protein kinase-phosphatase pair Stk1-Stp1 is, for instance, known for its ability to modulate the activities of the SarA family transcription factors MgrA, SarA, and SarZ [38], with Stp1 promoting infectivity, while Stk1 attenuates infectivity [5,38]. Stk1-driven phosphorylation of the catabolite control protein A was additionally shown to inhibit the DNA-binding capacity of the master regulator of carbon catabolite repression in S. aureus, thereby modulating the expression of metabolic and virulence genes [39], and infectivity [40]. Our findings, presented here and elsewhere [8], demonstrate that the deletion of $p t p B$ in the clinical S. aureus isolate SA564 alters the transcription of various genes/operons whose products are involved in stress adaptation and infectivity, suggesting that PtpB-driven removal of phosphates from arginine phosphosites is another posttranscriptional mechanism utilized by this pathogen to fine-tune the expression and activity of its virulon, in order to successfully adapt to the diverse host environmental conditions encountered by the bacterium during infection. Given the clear impact of PtpB on the transcription of specific virulence determinants shown here, its impact on S. aureus to cause disease in mice [8], and the fact that several low molecular weight protein tyrosine phosphatase inhibitors are currently in development to combat diseases such as cancer, diabetes/obesity, and bacterial infections [41-45], PtpB might constitute an additional interesting target for drug development against this notorious human nosocomial pathogen.

\section{Materials and Methods}

\subsection{Bacterial Strains, Media, and Growth Conditions}

The bacterial strains used in this study are listed in Table 1. S. aureus isolates were plated on Tryptic Soy Agar (TSA; BD, Heidelberg, Germany), or grown in Tryptic Soy Broth (TSB; BD) medium at $37^{\circ} \mathrm{C}$ and $225 \mathrm{rpm}$ with a culture to flask volume of 1:10.

Table 1. Strains used in this study.

\begin{tabular}{ccc}
\hline Strain & Description $^{\text {1 }}$ & Reference \\
\hline SA564 & S. aureus clinical isolate, wild type & {$[12]$} \\
SA564 $\Delta p t p B$ & SA564 $\Delta p t p B::$ lox66-erm(B)-lox71; Erm ${ }^{\mathrm{R}}$ & {$[8]$} \\
SA564 $\Delta p t p B:: p t p B$ & cis-complemented SA564 $\Delta p t p B$ derivative & {$[8]$} \\
\hline
\end{tabular}

${ }^{1}$ Erm $^{\mathrm{R}}$, erythromycin-resistant. 


\subsection{Human Whole Blood Phagocytosis Assay}

The uptake of $S$. aureus cells by PMNs in whole blood was performed essentially as described in [46]. Overnight cultures of S. aureus strains SA564, SA564 $\Delta p t p B$, and SA564 $\triangle p t p B:: p t p B$ were inoculated into fresh TSB to an optical density at $600 \mathrm{~nm}\left(\mathrm{OD}_{600}\right)$ of 0.05 and grown at $37{ }^{\circ} \mathrm{C}$ and $225 \mathrm{rpm}$ to mid-exponential growth-phase (i.e., $2 \mathrm{~h}$ ). Cultures were centrifuged at $10,000 \times g$ for $5 \mathrm{~min}$, bacterial pellets washed three times with phosphate buffered saline (PBS; Thermo Fisher, Dreieich, Germany), and subsequently stained with a $50 \mu \mathrm{M}$ carboxy fluorescein diacetate succinimidyl ester (CFSE; Invitrogen, Darmstadt, Germany)-PBS solution for $15 \mathrm{~min}$ at $37^{\circ} \mathrm{C}$ and $1000 \mathrm{rpm}$. CFSE-stained bacterial cells were afterwards washed again three times with PBS to remove unbound dye, and adjusted to an $\mathrm{OD}_{600}$ of 1 . Fresh human whole blood was withdrawn from healthy donors and anticoagulated with lithium heparin (S-Monovette; Sarstedt, Nümbrecht, Germany). The PMN contents of the blood samples were determined using the RAL DIFF-QUICK kit (RAL Diagnostics, Martillac, France) according to the manufacturer's recommendations, and blood samples were substituted with fluorescent-labeled bacteria at an MOI of 50 per PMN. Infected blood samples were cultured in the dark at $37^{\circ} \mathrm{C}$ and $1000 \mathrm{rpm}$ for $30 \mathrm{~min}$ and subsequently placed into $5 \mathrm{~mL}$ round bottom polystyrene tubes (BD). Erythrocytes were lysed by adding FACS lysis solution (BD), and lysed cell debris was removed by centrifugation at $450 \times g$ for $5 \mathrm{~min}$. The cell pellets were resuspended in PBS supplemented with $2 \%$ fetal calf serum (PAA, Pasching, Germany) and $0.05 \%$ sodium azide, and subjected to flow cytometry using a FACSCalibur (BD) system. PMNs were gated using the CellQuest Pro Software version 4.02 (BD), and the mean fluorescence intensity (MFI) per PMN was recorded, indicating the number of bacteria that were attached to or ingested by the leukocyte.

\subsection{Extracellular DNase-, Hemolytic- and Proteolytic Activity Assays}

Overnight cultures of the $S$. aureus SA564 strain triplet were adjusted for all three assays with fresh TSB to an $\mathrm{OD}_{600}$ of 12 . For extracellular DNase activity measurements, $5 \mu \mathrm{L}$ of the adjusted bacterial suspensions were spotted on DNase-Test-Agar plates (Carl Roth, Karlsruhe, Germany) and incubated for $24 \mathrm{~h}$ at $37^{\circ} \mathrm{C}$. Lytic zones were visualized by overlaying the agar with $1 \mathrm{~N} \mathrm{HCl}$ to precipitate undigested DNA. The hemolytic activities of the bacterial cell suspensions were tested by spotting $5 \mu \mathrm{L}$ aliquots of the bacterial suspensions on TSA II plates supplemented with $5 \%$ Sheep Blood (BD), and diameters of hemolytic zones were determined after $24 \mathrm{~h}$ of incubation at $37^{\circ} \mathrm{C}$. The proteolytic activity of the bacterial cell suspensions was determined by spotting $2 \mu \mathrm{L}$ aliquots of the bacterial suspensions on TSA plates supplemented with $10 \%$ skim milk (BD). Variations in zones of proteolysis were evaluated after incubating the plates for $48 \mathrm{~h}$ at $37^{\circ} \mathrm{C}$.

\subsection{Triton X-100 Induced Autolysis Assay}

Triton X-100 induced autolysis of S. aureus was assayed using a modified version of the protocol described in [47]. Cells of S. aureus SA564 and its $p t p B$ deletion mutant were cultured in TSB at $37^{\circ} \mathrm{C}$ and $225 \mathrm{rpm}$ to an $\mathrm{OD}_{600}$ of 0.7 , washed twice in ice-cold water, and resuspended in $0.05 \mathrm{M}$ Tris- $\mathrm{HCl}(\mathrm{pH} 7.2)$ containing $0.01 \%$ (vol/vol) Triton X-100 (Merck, Darmstadt, Germany). The cell suspensions were incubated at $30{ }^{\circ} \mathrm{C}$ and $225 \mathrm{rpm}$ and the $\mathrm{OD}_{600}$ measured every $30 \mathrm{~min}$. Triton X-100 induced autolysis was determined as the decline of optical density versus time and is expressed as the percent of the initial optical density.

\subsection{Lysostaphin Induced Autolysis Assay}

The lysostaphin-induced autolysis of S. aureus was assayed as described in [48]. Cells of S. aureus SA564 and SA564 $\triangle p t p B$ were cultured in TSB at $37^{\circ} \mathrm{C}$ and $225 \mathrm{rpm}$ to an $\mathrm{OD}_{600}$ of 3, washed twice in PBS, and resuspended in PBS to an $\mathrm{OD}_{600}$ of 1 . Cell suspensions were supplemented with $250 \mathrm{ng} / \mathrm{mL}$ of lysostaphin (Dr. Petry Genmedics GMBH, Reutlingen, Germany) and incubated under static conditions at $30^{\circ} \mathrm{C}$ for $60 \mathrm{~min}$. The $\mathrm{OD}_{600}$ was 
measured every $10 \mathrm{~min}$. Lysostaphin-induced autolysis was determined as the decline of optical density versus time and is expressed as the percent of the initial optical density.

\section{6. qRT-PCR Analyses}

RNA isolation, cDNA synthesis, and qRT-PCR were carried out as previously described [49], using the primer pairs listed in Table 2. Transcripts were quantified in reference to the transcription of gyrase $\mathrm{B}$ using the $2^{-\Delta \mathrm{Ct}}$ method [50].

Table 2. qRT-PCR primer used in this study.

\begin{tabular}{|c|c|c|}
\hline Gene Target & Primer & Sequence $\left(5^{\prime}-3^{\prime}\right)$ \\
\hline \multirow[b]{2}{*}{ atlR } & forward & AACTTATTACACTGACTAACAATG \\
\hline & reverse & TGTCCAAATCTTCTATTCACTAA \\
\hline \multirow{2}{*}{ aur } & forward & AATAGTATTGACGGTGGATTT \\
\hline & reverse & AATGCTGATAATTTACCTTGATG \\
\hline \multirow{2}{*}{$e b h$} & forward & GTAATAATGAACAGACTGAGAATC \\
\hline & reverse & AGCGGATAATGATTGACTATT \\
\hline \multirow{2}{*}{$f m t B$} & forward & GATGCTTCAAGAATTACAACAA \\
\hline & reverse & ATCCTGAGAATAGACCTACAT \\
\hline \multirow{2}{*}{ gyrB } & forward & GACTGATGCCGATGTGGA \\
\hline & reverse & AACGGTGGCTGTGCAATA \\
\hline \multirow{2}{*}{ hla } & forward & AACCCGGTATATGGCAATCAACT \\
\hline & reverse & CTGCTGCTTTCATAGAGCCATTT \\
\hline \multirow{2}{*}{ hld } & forward & AGGAGTGATTTCAATGGCACAAG \\
\hline & reverse & TGTGTCGATAATCCATTTTACTAAGTCA \\
\hline \multirow{2}{*}{$\operatorname{lrg} A$} & forward & GCCGGTATCTCAGTTGTTAACTCTT \\
\hline & reverse & AAATGGTGCTTGGCTAATGACAC \\
\hline \multirow{2}{*}{ lytN } & forward & CTATTGTCTTAAATGGTGATTATG \\
\hline & reverse & ATCTAAACTTTGGAACTTCATTA \\
\hline \multirow{2}{*}{ nuс } & forward & TAGCTCAGCAAATGCATCACAA \\
\hline & reverse & GAACCACTTCTATTTACGCCATTATCT \\
\hline \multirow{2}{*}{ psma } & forward & ATCAACAACTCATCACTATGTTAAATCAAC \\
\hline & reverse & GCCATCGTTTTGTCCTCCTGT \\
\hline \multirow{2}{*}{$p t p B$} & forward & AGCCCATTAGCGGAAAGTATTG \\
\hline & reverse & AAATTGATGATTTGGCATAACCTCT \\
\hline \multirow{2}{*}{ spa } & forward & TACTTATATCTGGTGGCGTAA \\
\hline & reverse & GGTCGTCTTTAAGACTTTGA \\
\hline \multirow{2}{*}{ splB } & forward & AAGGTAATGGTGGTATTTATTC \\
\hline & reverse & GAATGACTGATACATCTTCTTTA \\
\hline
\end{tabular}

\subsection{Statistical Analyses}

The statistical significance of changes between groups was determined using the GraphPad software package Prism 6.01. $p$ values $<0.05$ were considered statistically significant.

Author Contributions: Conceptualization, V.M. and M.B.; methodology, M.I.E. and M.B.; formal analysis, M.I.E. and M.B.; investigation, M.I.E.; resources, M.B. and S.L.B.; writing—original draft preparation, M.B.; writing-review and editing, M.I.E., V.M., S.L.B. and M.B. All authors have read and agreed to the published version of the manuscript.

Funding: This work was supported by grants from the ATIP/AVENIR Program for V.M., M.I.E. acknowledges support by the German Egyptian Research Long-Term Scholarship Program (GERLS). We acknowledge the support by the DFG and Saarland University within the funding program Open Access Publishing. 
Institutional Review Board Statement: The study was conducted according to the guidelines of the Declaration of Helsinki and approved by the Ethics Committee of the Medical Association of Saarland (code number 39/20, approved 25 February 2020).

Informed Consent Statement: Informed consent was obtained from all subjects involved in the study.

Data Availability Statement: The datasets generated during and/or analyzed during the current study are available from the corresponding author on reasonable request.

Acknowledgments: The authors thank Karin Hilgert for excellent technical support.

Conflicts of Interest: The authors declare no conflict of interest.

\section{References}

1. Haag, A.F.; Fitzgerald, J.R.; Penadés, J.R. Staphylococcus aureus in Animals. Microbiol. Spectr. 2019, 7. [CrossRef]

2. Bischoff, M.; Rhomby, P. Genetic Regulation. In Staphylococcus: Genetics and Physiology; Somerville, G.A., Ed.; Caister Academic Press: Cambridge, MA, USA, 2016; pp. 301-334.

3. Balasubramanian, D.; Harper, L.; Shopsin, B.; Torres, J.V. Staphylococcus aureus Pathogenesis in Diverse Host Environments. Pathog. Dis. 2017, 75. [CrossRef] [PubMed]

4. Jenul, C.; Horswill, A.R. Regulation of Staphylococcus aureus Virulence. Microbiol. Spectr. 2019, 7. [CrossRef]

5. Burnside, K.; Lembo, A.; Reyes, M.D.L.; Iliuk, A.; BinhTran, N.-T.; Connelly, J.E.; Lin, W.-J.; Schmidt, B.Z.; Richardson, A.R.; Fang, F.C.; et al. Regulation of Hemolysin Expression and Virulence of Staphylococcus aureus by a Serine/Threonine Kinase and Phosphatase. PLoS ONE 2010, 5, e11071. [CrossRef]

6. Junker, S.; Maaß, S.; Otto, A.; Hecker, M.; Becher, D. Toward the Quantitative Characterization of Arginine Phosphorylations in Staphylococcus aureus. J. Proteom. Res. 2019, 18, 265-279.

7. Junker, S.; Maaß, S.; Otto, A.; Michalik, S.; Morgenroth, F.; Gerth, U.; Hecker, M.; Becher, D. Spectral Library Based Analysis of Arginine Phosphorylations in Staphylococcus aureus. Mol. Cell. Proteom. 2018, 17, 335-348. [CrossRef]

8. Elhawy, M.I.; Huc-Brandt, S.; Pätzold, L.; Gannoun-Zaki, L.; Abdrabou, A.M.M.; Bischoff, M.; Molle, V. The Phos-Phoarginine Phosphatase PtpB from Staphylococcus aureus Is Involved in Bacterial Stress Adaptation During Infection. Cells 2021, 10, 645. [CrossRef]

9. Wozniak, D.J.; Tiwari, K.B.; Soufan, R.; Jayaswal, R.K. The McsB Gene of the ClpC Operon Is Required for Stress Tolerance and Virulence in Staphylococcus aureus. Microbiology 2012, 158, 2568-2576. [CrossRef] [PubMed]

10. Trentini, D.B.; Suskiewicz, M.J.; Heuck, A.; Kurzbauer, R.; Deszcz, L.; Mechtler, K.; Clausen, T. Arginine Phosphorylation Marks Proteins for Degradation by a Clp Protease. Nature 2016, 539, 48-53. [CrossRef] [PubMed]

11. Fuhrmann, J.; Schmidt, A.; Spiess, S.; Lehner, A.; Turgay, K.; Mechtler, K.; Charpentier, E.; Clausen, T. McsB Is a Protein Arginine Kinase That Phosphorylates and Inhibits the Heat-Shock Regulator CtsR. Science 2009, 324, 1323-1327. [CrossRef] [PubMed]

12. Somerville, G.A.; Beres, S.B.; Fitzgerald, J.R.; DeLeo, F.R.; Cole, R.L.; Hoff, J.S.; Musser, J.M. In Vitro Serial Passage of Staphylococcus aureus: Changes in Physiology, Virulence Factor Production, and Agr Nucleotide Sequence. J. Bacteriol. 2002, 184, $1430-1437$. [CrossRef]

13. Giraud, C.; Hausmann, S.; Lemeille, S.; Prados, J.; Redder, P.; Linder, P. The C-Terminal Region of the RNA Helicase CshA Is Required for the Interaction with the Degradosome and Turnover of Bulk RNA in the Opportunistic Pathogen Staphylococcus aureus. RNA Biol. 2015, 12, 658-674. [CrossRef] [PubMed]

14. Novick, R.P.; Ross, H.F.; Projan, S.J.; Kornblum, J.; Kreiswirth, B.; Moghazeh, S. Synthesis of Staphylococcal Virulence Factors Is Controlled by a Regulatory RNA Molecule. EMBO J. 1993, 12, 3967-3975. [CrossRef]

15. Mayadas, T.N.; Cullere, X.; Lowell, C.A. The Multifaceted Functions of Neutrophils. Annu. Rev. Pathol. Mech. Dis. 2014, 9, 181-218. [CrossRef] [PubMed]

16. Berends, E.T.; Horswill, A.R.; Haste, N.M.; Monestier, M.; Nizet, V.; Von Köckritz-Blickwede, M. Nuclease Expression by Staphylococcus aureus Facilitates Escape from Neutrophil Extracellular Traps. J. Innate Immun. 2010, 2, 576-586. [CrossRef] [PubMed]

17. Eisenbeis, J.; Saffarzadeh, M.; Peisker, H.; Jung, P.; Thewes, N.; Preissner, K.T.; Herrmann, M.; Molle, V.; Geisbrecht, B.V.; Jacobs, K.; et al. The Staphylococcus aureus Extracellular Adherence Protein Eap Is a DNA Binding Protein Capable of Blocking Neutrophil Extracellular Trap Formation. Front. Cell. Infect. Microbiol. 2018, 8, 235. [CrossRef] [PubMed]

18. Jusko, M.; Potempa, J.; Kantyka, T.; Bielecka, E.; Miller, H.K.; Kalinska, M.; Dubin, G.; Garred, P.; Shaw, L.N.; Blom, A.M. Staphylococcal Proteases Aid in Evasion of the Human Complement System. J. Innate Immun. 2014, 6, 31-46. [CrossRef] [PubMed]

19. Shaw, L.; Golonka, E.; Potempa, J.; Foster, S.J. The Role and Regulation of the Extracellular Proteases of Staphylococcus aureus. Microbiology 2004, 150, 217-228. [CrossRef] [PubMed]

20. Sahl, H.-G.; Pag, U.; Bonness, S.; Wagner, S.; Antcheva, N.; Tossi, A. Mammalian Defensins: Structures and Mechanism of Antibiotic Activity. J. Leukoc. Biol. 2004, 77, 466-475. [CrossRef]

21. Schindler, C.A.; Schuhardt, V.T. Purification and Properties of lysostaphin-A Lytic Agent for Staphylococcus aureus. Biochim. Biophys. Acta (BBA) Gen. Subj. 1965, 97, 242-250. [CrossRef] 
22. Koehl, J.L.; Muthaiyan, A.; Jayaswal, R.K.; Ehlert, K.; Labischinski, H.; Wilkinson, B.J. Cell Wall Composition and Decreased Autolytic Activity and Lysostaphin Susceptibility of Glycopeptide-Intermediate Staphylococcus aureus. Antimicrob. Agents Chemother. 2004, 48, 3749-3757. [CrossRef] [PubMed]

23. Trotonda, M.P.; Xiong, Y.Q.; Memmi, G.; Bayer, A.S.; Cheung, A.L. Role of MgrA and SarA in Methicillin-Resistant Staphylococcus aureus Autolysis and Resistance to Cell Wall-Active Antibiotics. J. Infect. Dis. 2009, 199, 209-218. [CrossRef] [PubMed]

24. Manna, A.C.; Ingavale, S.S.; Maloney, M.; Van Wamel, W.; Cheung, A.L. Identification of SarV (SA2062), a New Transcriptional Regulator, Is Repressed by SarA and MgrA (SA0641) and Involved in the Regulation of Autolysis in Staphylococcus aureus. J. Bacteriol. 2004, 186, 5267-5280. [CrossRef] [PubMed]

25. Luong, T.T.; Dunman, P.M.; Murphy, E.; Projan, S.J.; Lee, C.Y. Transcription Profiling of the MgrA Regulon in Staphylococcus aureus. J. Bacteriol. 2006, 188, 1899-1910. [CrossRef] [PubMed]

26. Crosby, H.A.; Schlievert, P.M.; Merriman, J.A.; King, J.M.; Salgado-Pabón, W.; Horswill, A.R. The Staphylococcus aureus Global Regulator MgrA Modulates Clumping and Virulence by Controlling Surface Protein Expression. PLoS Pathog. 2016, 12, e1005604. [CrossRef] [PubMed]

27. Groicher, K.H.; Firek, B.A.; Fujimoto, D.F.; Bayles, K.W. The Staphylococcus aureus LrgAB Operon Modulates Murein Hydrolase Activity and Penicillin Tolerance. J. Bacteriol. 2000, 182, 1794-1801. [CrossRef]

28. Sugai, M.; Fujiwara, T.; Komatsuzawa, H.; Suginaka, H. Identification and Molecular Characterization of a Gene Homologous to Epr (endopeptidase Resistance Gene) in Staphylococcus aureus. Gene 1998, 224, 67-75. [CrossRef]

29. Komatsuzawa, H.; Ohta, K.; Sugai, M.; Fujiwara, T.; Glanzmann, P.; Berger-Bächi, B.; Suginaka, H. Tn551-Mediated Insertional Inactivation of the FmtB Gene Encoding a Cell Wall-Associated Protein Abolishes Methicillin Resistance in Staphylococcus aureus. J. Antimicrob. Chemother. 2000, 45, 421-431. [CrossRef]

30. Fujimoto, D.F.; Brunskill, E.W.; Bayles, K.W. Analysis of Genetic Elements Controlling Staphylococcus aureus LrgAB Expression: Potential Role of DNA Topology in SarA Regulation. J. Bacteriol. 2000, 182, 4822-4828. [CrossRef]

31. Ziebandt, A.K.; Weber, H.; Rudolph, J.; Schmid, R.; Höper, D.; Engelmann, S.; Hecker, M. Extracellular Proteins of Staphylococcus aureus and the Role of SarA and Sigma B. Proteomics 2001, 1, 480-493. [CrossRef]

32. Dunman, P.M.; Murphy, E.; Haney, S.; Palacios, D.; Tucker-Kellogg, G.; Wu, S.; Brown, E.L.; Zagursky, R.J.; Shlaes, D.; Projan, S.J. Transcription Profiling-Based Identification of Staphylococcus aureus Genes Regulated by the Agr and/Or SarA Loci. J. Bacteriol. 2001, 183, 7341-7353. [CrossRef] [PubMed]

33. Chan, P.F.; Foster, S.J. Role of SarA in Virulence Determinant Production and Environmental Signal Trans-Duction in Staphylococcus aureus. J. Bacteriol. 1998, 180, 6232-6241. [CrossRef] [PubMed]

34. Cheung, A.L.; Projan, S.J. Cloning and Sequencing of sarA of Staphylococcus aureus, a Gene Required for the Expression of agr. J. Bacteriol. 1994, 176, 4168-4172. [CrossRef]

35. Novick, R.P. Autoinduction and Signal Transduction in the Regulation of Staphylococcal Virulence. Mol. Microbiol. 2003, 48, 1429-1449. [CrossRef] [PubMed]

36. Queck, S.Y.; Jameson-Lee, M.; Villaruz, A.E.; Bach, T.-H.L.; Khan, B.A.; Sturdevant, D.E.; Ricklefs, S.M.; Li, M.; Otto, M. RNAIIIIndependent Target Gene Control by the Agr Quorum-Sensing System: Insight into the Evolution of Virulence Regulation in Staphylococcus aureus. Mol. Cell 2008, 32, 150-158. [CrossRef] [PubMed]

37. Janczarek, M.; Vinardell, J.-M.; Lipa, P.; Karaś, M. Hanks-Type Serine/Threonine Protein Kinases and Phosphatases in Bacteria: Roles in Signaling and Adaptation to Various Environments. Int. J. Mol. Sci. 2018, 19, 2872. [CrossRef]

38. Sun, F.; Ding, Y.; Ji, Q.; Liang, Z.; Deng, X.; Wong, C.C.; Yi, C.; Zhang, L.; Xie, S.; Alvarez, S.; et al. Protein Cysteine Phosphorylation of SarA/MgrA Family Transcriptional Regulators Mediates Bacterial Virulence and Antibiotic Resistance. Proc. Natl. Acad. Sci. USA 2012, 109, 15461-15466. [CrossRef] [PubMed]

39. Leiba, J.; Hartmann, T.; Cluzel, M.E.; Cohen-Gonsaud, M.; Delolme, F.; Bischoff, M.; Molle, V. A Novel Mode of Regu-Lation of the Staphylococcus aureus Catabolite Control Protein a (CcpA) Mediated by Stk1 Protein Phosphorylation. J. Biol. Chem. 2012, 287, 43607-43619. [CrossRef] [PubMed]

40. Bischoff, M.; Wonnenberg, B.; Nippe, N.; Nyffenegger, N.; Voss, M.; Beisswenger, C.; Sunderkötter, C.; Molle, V.; Dinh, Q.T.; Lammert, F.; et al. CcpA Affects Infectivity of Staphylococcus aureus in a Hyperglycemic Environment. Front. Cell. Infect. Microbiol. 2017, 7, 172. [CrossRef]

41. Maccari, R.; Ottanà, R. Low Molecular Weight Phosphotyrosine Protein Phosphatases as Emerging Targets for the Design of Novel Therapeutic Agents. J. Med. Chem. 2011, 55, 2-22. [CrossRef]

42. Ruddraraju, K.V.; Aggarwal, D.; Zhang, Z.Y. Therapeutic Targeting of Protein Tyrosine Phosphatases from Mycobacterium tuberculosis. Microorganisms 2020, 9, 14. [CrossRef] [PubMed]

43. Pardella, E.; Pranzini, E.; Leo, A.; Taddei, M.L.; Paoli, P.; Raugei, G. Oncogenic Tyrosine Phosphatases: Novel Therapeutic Targets for Melanoma Treatment. Cancers 2020, 12, 2799. [CrossRef] [PubMed]

44. Zhang, Z.-Y. Drugging the Undruggable: Therapeutic Potential of Targeting Protein Tyrosine Phosphatases. Accounts Chem. Res. 2017, 50, 122-129. [CrossRef] [PubMed]

45. Stanford, S.M.; Aleshin, A.E.; Zhang, V.; Ardecky, R.J.; Hedrick, M.P.; Zou, J.; Ganji, S.R.; Bliss, M.R.; Yamamoto, F.; Bobkov, A.A.; et al. Diabetes Reversal by Inhibition of the Low-Molecular-Weight Tyrosine Phosphatase. Nat. Chem. Biol. 2017, 13, 624-632. [CrossRef] [PubMed] 
46. Ballhausen, B.; Jung, P.; Kriegeskorte, A.; Makgotlho, P.E.; Ruffing, U.; Von Müller, L.; Köck, R.; Peters, G.; Herrmann, M.; Ziebuhr, W.; et al. LA-MRSA CC398 Differ from Classical Community Acquired-MRSA and Hospital Acquired-MRSA Lineages: Functional Analysis of Infection and Colonization Processes. Int. J. Med Microbiol. 2014, 304, 777-786. [CrossRef] [PubMed]

47. Mani, N.; Tobin, P.; Jayaswal, R.K. Isolation and Characterization of Autolysis-Defective Mutants of Staphylococcus aureus Created by Tn917-LacZ Mutagenesis. J. Bacteriol. 1993, 175, 1493-1499. [CrossRef]

48. Peschel, A.; Vuong, C.; Otto, M.; Götz, F.; Cole, A.M.; Darouiche, R.O.; Legarda, D.; Connell, N.; Diamond, G. The D-Alanine Residues of Staphylococcus aureus Teichoic Acids Alter the Susceptibility to Vancomycin and the Activity of Autolytic Enzymes. Antimicrob. Agents Chemother. 2000, 44, 2039-2045. [CrossRef]

49. Chatterjee, I.; Becker, P.; Grundmeier, M.; Bischoff, M.; Somerville, G.A.; Peters, G.; Sinha, B.; Harraghy, N.; Proctor, R.A.; Herrmann, M. Staphylococcus aureus ClpC Is Required for Stress Resistance, Aconitase Activity, Growth Recovery, and Death. J. Bacteriol. 2005, 187, 4488-4496. [CrossRef] [PubMed]

50. Pfaffl, M.W. Relative Quantification. In Real-Time PCR; Tevfik Dorak, M., Ed.; Taylor \& Francis: Abingdon, UK, 2006 ; pp. 63-82. 